\title{
A Novel Vector Control of Five-phase PMSM Based on Harmonic Current Closed Loop
}

\author{
Yu Fei, Zhou Yongchao \\ Dept. of Electrical Eng., Naval Univ. of Engineering, Wuhan 430033, China
}

\begin{abstract}
Multi-phase electric machines such as five-phase permanent magnet synchronous motor (PMSM) play an important role in the ships electrical propulsion because of the advantages of high performance and high reliability. The decoupled mathematic models of five-phase PMSM in dq coordinate frame are established, and the reason caused to high stator harmonic current in the multi-phase motor is analyzed based on the mathematic models. To suppress the harmonic current, a novel vector control (VC) method based on SVPWM and harmonic current closed loop control is proposed. Based on the proposed algorithm, a five-phase PMSM vector control system is established with MATLAB, the performance is simulated and analyzed. The results show that, the stator harmonic current is much little than that of the traditional control method.
\end{abstract}

\section{Introduction}

Variable speed control of multi-phase motor is an important technology in high performance and high power electrical drive field, which has been widely applied to the ships electrical propulsion. The so-called multi-phase motor meant that the phases of the motor are more than three phases, such as five-phase reluctance motor, six-phase induction motor, twelve-phase synchronous motor, and so on. When the phases of the motor increase, it not only reduces the power requirements of the frequency converter bridge arm, but also helps to reduce the torque ripple of the propulsion motor, noise and network side harmonics. If some phase windings of the motor fault, it can continue to work with low power condition, which improves the safety of the system. So the multi-phase propulsion motor is an important development direction in ship electrical propulsion.

Due to the particularity of the multi-phase motors' structure, the mathematical model and the control method of the multi-phase motor are different from the traditional three-phase motor. Some literatures try to apply the traditional three-phase motor control methods to multi-phase systems directly, such as the twelve-pulse scalar control of six-phase motors [1], the vector control of multi-phase Permanent Magnet Synchronous Motor (PMSM) based on current hysteresis PWM [2], and so on. However, some studies find that the current harmonics of the multi-phase motor are significantly larger than the three-phase motor in the traditional control mode [3]. The main reason is that it did not take into account the specificity of the multi-phase motor itself. In this paper, five-phase permanent magnet synchronous motor (PMSM) is taking as an example to analyse the causes of excessive harmonic currents generated by the multi-phase motors based on the detailed modelling of the motor, and a multi - phase motor vector control method based on SVPWM and harmonic current closed-loop is proposed. By the proposed method, the harmonic current are suppressed effectively, and the motor control performance is enhanced at the same time.

\section{Mathematical models of five-phase PMSM}

\subsection{Mathematical models of five-phase PMSM in the abc coordinate system}

According to the basic circuit principle, the mathematical models of five-phase PMSM in the abc coordinate system can be got as follows:

$$
\begin{aligned}
& \mathbf{u}_{\mathrm{s}}=\mathbf{R}_{\mathrm{s}} \mathbf{i}_{\mathrm{s}}+p \boldsymbol{\psi}_{\mathrm{s}} \\
& \boldsymbol{\psi}_{\mathrm{s}}=\mathbf{L}_{\mathrm{ss}} \mathbf{i}_{\mathrm{s}}+\boldsymbol{\psi}_{\mathrm{fs}}
\end{aligned}
$$

Where,

$$
\begin{aligned}
& \mathbf{u}_{\mathbf{s}}=\left[\begin{array}{lllll}
u_{a} & u_{b} & u_{c} & u_{d} & u_{e}
\end{array}\right]^{\mathrm{T}} \text {, } \\
& \mathbf{i}_{\mathbf{s}}=\left[\begin{array}{lllll}
i_{a} & i_{b} & i_{c} & i_{d} & i_{e}
\end{array}\right]^{\mathrm{T}}, \\
& \boldsymbol{\psi}_{\mathbf{s}}=\left[\begin{array}{lllll}
\psi_{a} & \psi_{b} & \psi_{c} & \psi_{d} & \psi_{e}
\end{array}\right]^{\mathrm{T}}, \\
& \mathbf{R}_{\mathbf{s}}=\operatorname{diag}\left(\begin{array}{lllll}
r_{s} & r_{s} & r_{s} & r_{s} & r_{s}
\end{array}\right) \text {, } \\
& \boldsymbol{\psi}_{\mathrm{fs}}=\left[\begin{array}{lllll}
\psi_{a f} & \psi_{b f} & \psi_{c f} & \psi_{d f} & \psi_{e f}
\end{array}\right]^{T} .
\end{aligned}
$$

$\boldsymbol{\psi}_{\mathrm{fs}}$ is the magnetic flux generated by the permanent magnet flux linkage through the stator winding, and

*Corresponding author: gfnui999@163.com 
$\psi_{i f}=\psi_{f m} \cos [\theta-(i-1) 2 \pi / n], i=1,2,3,4,5$

Where $\psi_{f m}$ is the maximum flux generated by the permanent magnet in the stator windings.

Various inductors can be calculated by the structure of the motor using the double reaction principle.

The Stator winding self-inductance is :

$$
L_{i i}=L_{11 l}+L_{m m 0}+L_{m m 2} \cos 2\left(\theta-(i-1) \frac{2 \pi}{n}\right)
$$

The Stator winding mutual inductance is:

$$
L_{j i}=L_{m m 0} \cos \left[(i-j) \frac{2 \pi}{n}\right]+L_{m m 2} \cos \left[2 \theta-(i+j-2) \frac{2 \pi}{n}\right]
$$

(4)

In the formula $i, j=1,2,3,4,5$

$$
\begin{aligned}
& L_{m m 0}=\left(\frac{2}{\pi} \frac{w_{s} k_{w}}{a}\right)^{2} \cdot \frac{l \tau}{p} \cdot \frac{\lambda_{d}+\lambda_{q}}{2}, \\
& L_{m m 2}=\left(\frac{2}{\pi} \frac{w_{s} k_{w}}{a}\right)^{2} \cdot \frac{l \tau}{p} \cdot \frac{\lambda_{d}-\lambda_{q}}{2} .
\end{aligned}
$$

\subsection{The mathematical models of five-phase PMSM in dq coordinate system}

In the case of inverter power supply, the motor input currents and voltages are not standard sine waves, in addition to the fundamental it contains a series of harmonics. In order to consider the role of fundamental and harmonics simultaneously, we define the decoupled transformation matrix for a five-phase motor as shown in(5).

$$
T_{d q 0}^{a b c}=\sqrt{\frac{2}{5}}\left[\begin{array}{ccccc}
\cos (\theta) & \cos \left(\theta-\frac{2 \pi}{5}\right) & \cos \left(\theta-\frac{4 \pi}{5}\right) & \cos \left(\theta-\frac{6 \pi}{5}\right) & \cos \left(\theta-\frac{8 \pi}{5}\right) \\
-\sin (\theta) & -\sin \left(\theta-\frac{2 \pi}{5}\right) & -\sin \left(\theta-\frac{4 \pi}{5}\right) & -\sin \left(\theta-\frac{6 \pi}{5}\right) & -\sin \left(\theta-\frac{8 \pi}{5}\right) \\
\cos (\theta) & \cos \left(\theta-\frac{6 \pi}{5}\right) & \cos \left(\theta-\frac{2 \pi}{5}\right) & \cos \left(\theta-\frac{8 \pi}{5}\right) & \cos \left(\theta-\frac{4 \pi}{5}\right) \\
-\sin (\theta) & -\sin \left(\theta-\frac{6 \pi}{5}\right) & -\sin \left(\theta-\frac{2 \pi}{5}\right) & -\sin \left(\theta-\frac{8 \pi}{5}\right) & -\sin \left(\theta-\frac{4 \pi}{5}\right) \\
1 / \sqrt{2} & 1 / \sqrt{2} & 1 / \sqrt{2} & 1 / \sqrt{2} & 1 / \sqrt{2}
\end{array}\right]
$$

In the transforming matrix above, the elements in the first row and second row are correspond to the fundamental component, the elements in the third and fourth row are correspond to the third harmonic component, and the elements in the fifth row are corresponds to the zero sequence component. Using the matrix to transform equations in abc coordinate system into dq coordinate system, that are:

$$
\left[\begin{array}{l}
u_{d 1} \\
u_{d 1} \\
u_{d 3} \\
u_{d 3} \\
u_{0}
\end{array}\right]=\left[\begin{array}{lllll}
r_{s} & & & \\
r_{s} & & \\
& r_{s} & & \\
& & & \\
& & & \\
& & & \\
& & & \\
& &
\end{array}\right]\left[\begin{array}{l}
i_{d 1} \\
i_{q 1} \\
i_{d 3} \\
i_{q 3} \\
i_{0}
\end{array}\right]+\left[\begin{array}{lllll}
0 & -\omega & 0 & 0 & 0 \\
\omega & 0 & 0 & 0 & 0 \\
0 & 0 & 0 & 0 & 0 \\
0 & 0 & 0 & 0 & 0 \\
0 & 0 & 0 & 0 & 0
\end{array}\right]\left[\begin{array}{l}
\psi_{d 1} \\
\psi_{q 1} \\
\psi_{d 3} \\
\psi_{q 3} \\
\psi_{0}
\end{array}\right]+p\left[\begin{array}{l}
\psi_{d 1} \\
\psi_{q 1} \\
\psi_{d 3} \\
\psi_{q 3} \\
\psi_{0}
\end{array}\right]
$$

$$
\left[\begin{array}{l}
\psi_{d 1} \\
\psi_{q 1} \\
\psi_{d 3} \\
\psi_{q 3} \\
\psi_{0}
\end{array}\right]=\left[\begin{array}{ccccc}
L_{d} & 0 & 0 & 0 & 0 \\
0 & L_{\mathrm{q}} & 0 & 0 & 0 \\
0 & 0 & L_{s l} & 0 & 0 \\
0 & 0 & 0 & L_{s l} & 0 \\
0 & 0 & 0 & 0 & L_{s l}
\end{array}\right]\left[\begin{array}{c}
i_{d 1} \\
i_{q 1} \\
i_{d 3} \\
i_{q 3} \\
i_{0}
\end{array}\right]+\left[\begin{array}{c}
\psi_{f} \\
0 \\
0 \\
0 \\
0
\end{array}\right]
$$

In the formula $L_{d}=L_{s l}+\frac{5}{2}\left(L_{m m 0}+L_{m m 2}\right)$,

Substituting the flux equation into the voltage equation, the harmonic voltage equations of the motor are:

$$
\begin{aligned}
& u_{d 3}=r_{s} i_{d 3}+L_{s l} \frac{d i_{d 3}}{d t} \\
& u_{q 3}=r_{s} i_{q 3}+L_{s l} \frac{d i_{q 3}}{d t}
\end{aligned}
$$

electromagnetic torque equation:

$$
\begin{aligned}
& T_{e m}=\left.\frac{1}{2} p_{m} \frac{\partial}{\partial \theta}\left(\mathbf{i}^{\mathrm{T}} \boldsymbol{\psi}\right)\right|_{i}=\text { const } \\
& =p_{m}\left(\psi_{d 1} i_{q 1}-\psi_{q 1} i_{d 1}\right)=p_{m}\left[\psi_{f} i_{q 1}+\left(L_{d}-L_{q}\right) i_{d 1} i_{q 1}\right]
\end{aligned}
$$

From the harmonic voltage equation (8) and (9), we can see that the harmonic current relate only with the stator resistance and self-leakage. The values of these two parameters are generally small, so in a multi-phase motor, if no special control is adopting, it will produce harmonic current much larger than the traditional threephase motor. Although this harmonic current has no effect on the torque, it can cause stator heating and large losses.

\section{Five-phase PMSM vector control based on SVPWM and harmonic current closed Loop}

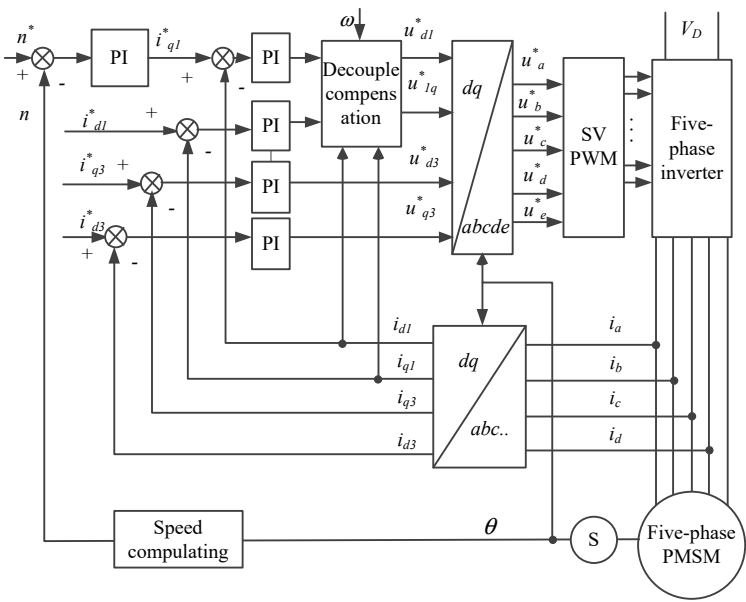

Figure 1. Vector control of five-phase PMSM

From the harmonic voltage equation, it can be seen that the harmonic current of the motor is only determined by the corresponding harmonic voltage and independent of the other energies. So the simplest way to suppress 
harmonic current is to control the harmonic current directly by closed-loop. At the same time, in order to fix the switching frequency and improve the torque performance, a five-phase SVPWM [4-6] control method can be introduced into the vector control to improve the overall performance of the motor.

The block diagram of rotor field oriented vector control for five-phase PMSM based on the closed-loop control of harmonic current method is shown in Figure 1.

Seen from Figure 1, the system adds two harmonic current closed-loops in order to suppress the harmonic current by setting the given harmonic current to zero, that is $i_{\mathrm{d} 3}^{*}=i_{\mathrm{q} 3}^{*}=0$. The current loop is achieved by $\mathrm{d}, \mathrm{q}$ component, rather than the current hysteresis PWM used in the abc component. The corresponding dq-axis current is obtained by the motor feedback current through fulldimensional decoupling transform. Since $i_{0}$ is the zero sequence current component in five-phase motor, it flows nowhere in a star winding configuration without a neutral point. So it needs not to be controlled. The reference voltage is derived from the reference current by the PI regulator. Seen from dq voltage equation that, $\mathrm{d}_{3}, \mathrm{q}_{3}$ axis components are completely decoupled, and they are decoupled from the $\mathrm{d}_{1}, \mathrm{q}_{1}$ axis components also. Therefore, it is feasible getting reference voltage from the current difference directly by PI controller. However, although the $\mathrm{d}_{1}, \mathrm{q}_{1}$ axis components are decoupled from the $d_{3}, q_{3}$ axis components, but they are not decoupled from each other even when using $i_{\mathrm{d} 1}=0$ control. $d_{1}$ axis voltage will be affected by $q_{1}$ axis current and speed, $\mathrm{q}_{1}$ axis voltage is also affected by the $\mathrm{d}_{1}$ axis current and speed.

In order to achieve decoupling between the $\mathrm{d}_{1}, \mathrm{q}_{1}$ axis components, it needs to introduce voltage compensation. According to $\mathrm{d}_{1}$ and $\mathrm{q}_{1}$ axis voltage equation, the following voltage compensation items are added after the $d_{1}, q_{1}$ axis current difference PI output:

$$
\begin{gathered}
u_{d 1}^{c}=-\omega L_{q} i_{q 1} \\
u_{q 1}^{c}=\omega\left(L_{d} i_{d 1}+\psi_{f}\right)
\end{gathered}
$$

Decoupling control block diagram is shown in Figure 2.

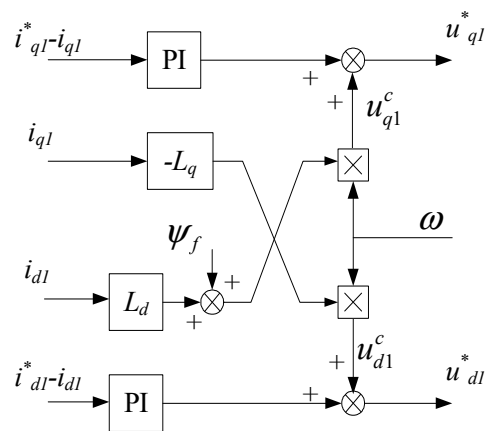

Figure 2. Decouple control of the voltages

\section{Simulation and comparison}

According to the control method given in Figure 1, a five-phase PMSM vector control simulation model by MATLAB / Simulink based on SVPWM is established.
The basic parameters of five-phase PMSM are shown in Table 1.

Table 1. Parameters of the five-phase PMSM

\begin{tabular}{|c|c|c|c|c|c|c|c|}
\hline Parameter & $p$ & $L_{d}$ & $L_{q}$ & $L_{s l}$ & $J$ & $R_{s}$ & $\Psi_{f}$ \\
\hline Value & 4 & $8 \mathrm{mH}$ & $8.5 \mathrm{mH}$ & $0.2 \mathrm{mH}$ & $0.004 \mathrm{~kg} \cdot \mathrm{m}^{2}$ & $1 \Omega$ & $0.175 \mathrm{~T}$ \\
\hline
\end{tabular}

The switching frequency of the inverter is $5 \mathrm{kHz}$, the DC link voltage is $300 \mathrm{~V}$. The system uses rotor fieldoriented vector control with $i_{\mathrm{d}}=0$. The given speed is $500 \mathrm{rad} / \mathrm{s}$. For comparison, the same simulation parameters are set for the method based on the traditional current hysteresis PWM in the multi-phase motor control. Switching frequency of two simulation methods is also transferred into the same in the steady state of the inverter. The simulation results are shown in Figure 3 to Figure 6.

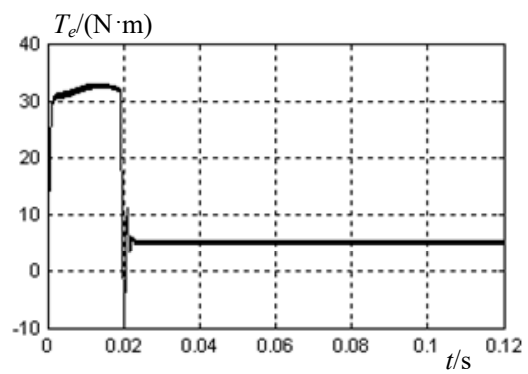

(a) Motor torque

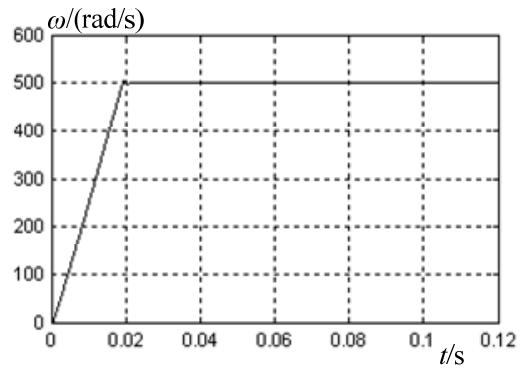

(b) Speed response

Figure 3. Torque and speed in harmonic current closed loop control

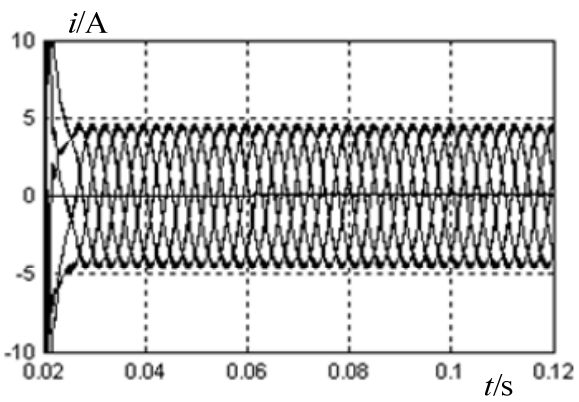

(a) Motor stator current 


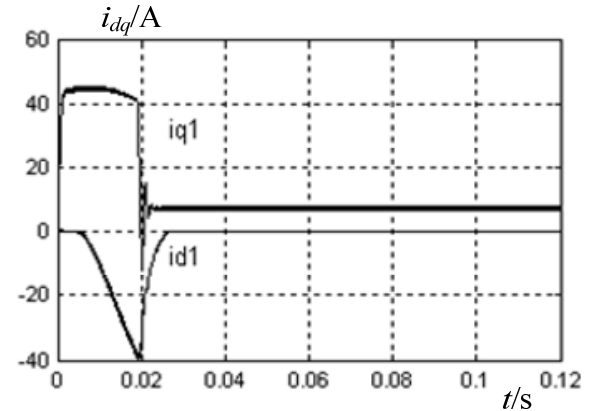

(b) $d_{1}$ axis, $q_{1}$ axis current

Figure 4. Current in harmonic current closed loop control

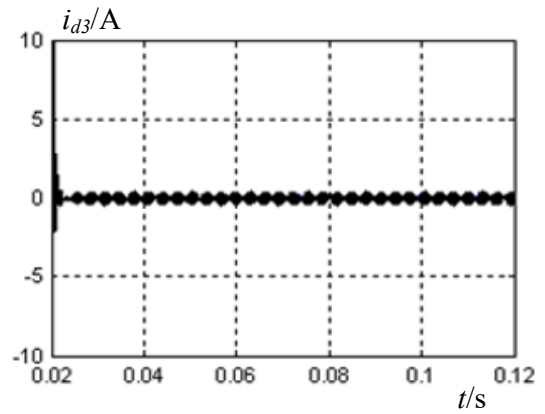

(a) Motor $\mathrm{d}_{3}$ axis current

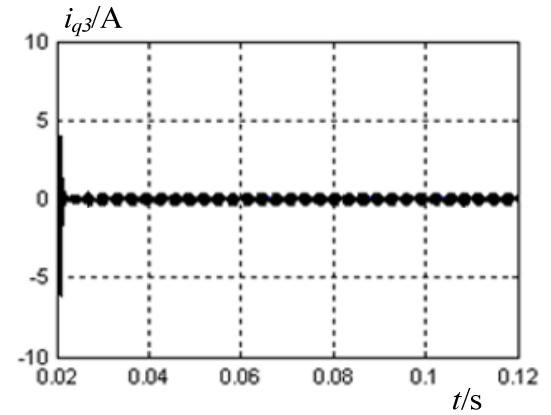

(b)Motor $\mathrm{q}_{3}$ axis current

Figure 5. $d_{3}$ and $q_{3}$ axis current in harmonic current closed loop control

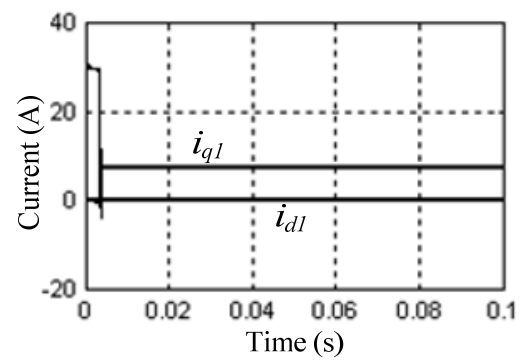

(a) $\mathrm{d}_{1}$ and $\mathrm{q}_{1}$ axis current

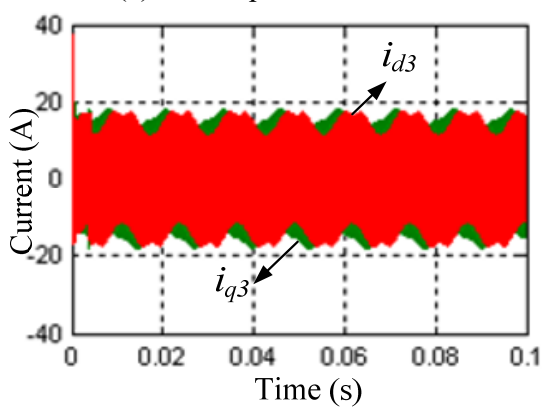

(b) $\mathrm{d}_{3}$ and $\mathrm{q}_{3}$ axis current

Figure 6. Current in the traditional control
From the simulation results, motor torque and speed response based on SVPWM and closed-loop control of harmonic current is very fast. The steady-state torque ripple is small, while its harmonic current is significantly less than the traditional control method.

\section{Conclusions}

In this paper, taking five-phase PMSM as an example, the mathematical modelS of the multi-phase motor in the abc coordinate system are established. Then they are transformed into a rotating coordinate system through a full-dimensional Park transformation matrix. The variables in the rotating coordinate system have decoupling properties. In terms of the analysis of the decoupled models, we can find that the harmonic current of the multi-phase motor are determined only by the corresponding harmonic voltage, stator resistance and leakage inductance. The value of stator resistance and leakage inductance are very small. So, if the harmonic voltage is not suppressed, it will cause very large harmonic current, which will cause high stator loss and heating.

In order to suppress the harmonic current, a vector control of multi-phase motor based on SVPWM and harmonic current closed loop is proposed. The method obtains the harmonic current component of the motor through the full-dimensional Park transformation, and then controls them to be zero by use of closed-loop. In addition, in order to improve the motor torque control performance, a high performance SVPWM algorithm is introduced. The rotor field oriented vector control of five-phase PMSM is established and its control performance is simulated. The simulation results show that the proposed control method has the advantages of fast dynamic response, small torque ripple and small harmonic current.

\section{References}

1. R H Neson, P C Krause. Induction machine analysis for arbitrary displacement between multiple winding sets. IEEE Trans. Power App. Syst., 1994, 18(3): 841-848.

2. Ruhe Shi and Hamid A. Toliyat. Vector Control of Five-Phase Synchronous Reluctance Motor with Space Vector Pulse Width Modulation (SVPWM) for Minimum Switching Losses. In Applied Power Electronics Conference and Exposition, 2002(APEC'2002). Seventeenth Annual IEEE, vol.1, March 2002, pp.57-63.

3. Fei Yu, Anzhou Zhu, Dong Xiang. A Novel Fivephase SVPWM Base on the Feature Harmonics Space Voltage Vectors Injecting. Proceedings of the international conference on Electrical Machines and Systems, Busan, Korea, 2013.10.26-29.

4. Tang Jun, Wang Tiecheng. Implementation Method of SVPWM for Five-Phase Inverters. Transactions of China Electrotechnical Society, 2013, 27(7): 6472 . 
5. Fei Yu, Dong Xiang, Yongqing Wei. Performance Analysis and Comparison of Five-phase Inverter SVPWMs. Proceedings of the 17th International Conference on Electrical Machines and Systems (ICEMS), Oct. 22-25, 2014, Hangzhou, China: $1410-1415$

6. Fei Yu, Mingzhong Qiao, Qingguo Song. Control and Performance of the Multiphase Inverter. Proceeding of 2011 Asia-Pacific Power and Energy Engineering Conference, 2011. 